\title{
A Model to Study Intramolecular $\pi-\pi$ Stacking Interactions
}

\author{
Flávio Sêga Pereira Cardoso and Aaron Aponick* \\ University of Florida, Department of Chemistry, P.O. Box 117200, Gainesville, FL, USA \\ *aponick@chem.ufl.edu
}

Keywords: biaryl, non-covalent interaction, $\pi$ - $\pi$ stacking

\section{INTRODUCTION}

Nature has evolved enzymes as effective catalysts in biological systems. The activity of these macromolecules is governed by a variety of noncovalent interactions. ${ }^{1}$ In particular, interactions involving aromatic units play an important role in the behavior of not only biological but also chemical systems. $^{2}$ In order to better understand this phenomena, designing chemical models to study these interactions is meaningful. Scheme $\mathbf{1}$ illustrates a general system containing 2 aromatic units connected by a "linker". Depending on the nature of the aromatic moieties and the "linker", the rings could be $\pi-\pi$ stacked or not.

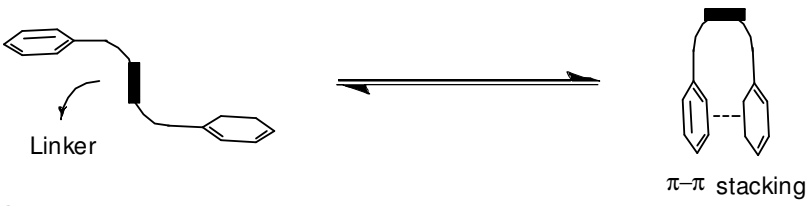

Scheme 1. Two possible conformations for the system.

\section{RESULTS AND DISCUSSION}

The model we decided to explore consists of a biaryl structure containing 3 aromatic units. The heteroaromatic ring $B$ is the "linker" and rings $A$ and $C$ can $\pi-\pi$ stack intramolecularly. To explore the viability of this interaction, compounds $\mathbf{1}$ and $\mathbf{2}$ were synthesized (Scheme 2).
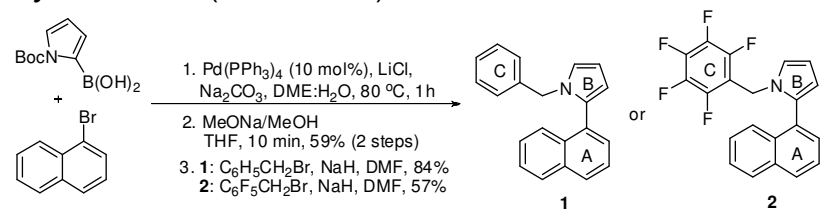

Scheme 2. Synthesis of compounds 1 and 2.

Surprisingly, ${ }^{1} \mathrm{H}$ NMR of 2 showed an $A B$ quartet at $4.92 \mathrm{ppm}$, suggesting a diastereotopic environment for the methylene protons. This result allows for the measurement of the barrier to rotation of the biaryl bonds using the coalescence method ${ }^{2}$ (Scheme 3). Considering that compounds $\mathbf{1}$ and $\mathbf{2}$ are isosteric, this difference in the barrier to rotation relies mainly on electronic factors. This means that there is a stabilization of $2.4 \mathrm{kcal} / \mathrm{mol}$ for compound 2 , most likely due to the well-known ability of perfluoroarene moieties to $\pi-\pi$ stack. $^{2}$

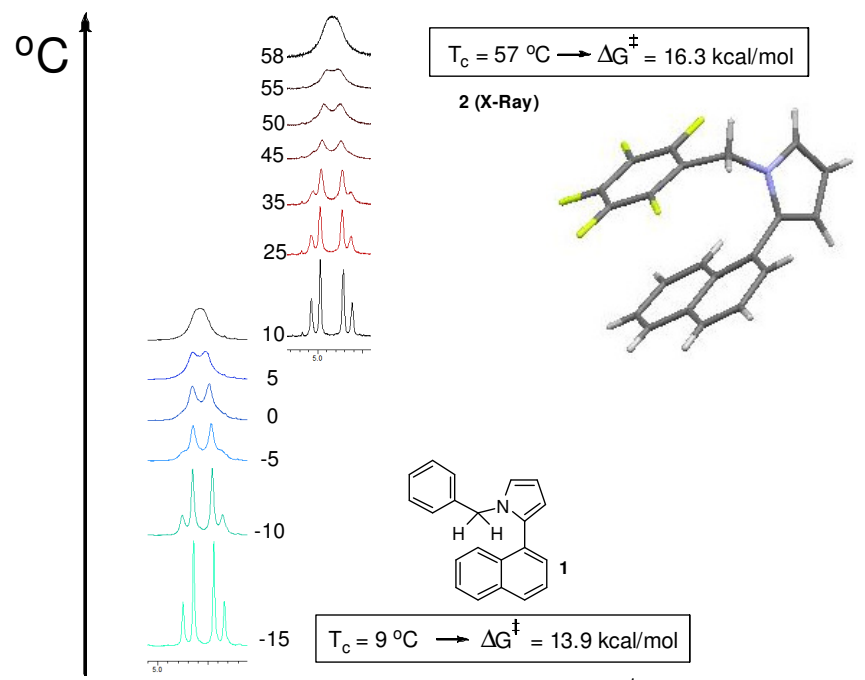

Scheme 3. Variable-Temperature ${ }^{1} \mathrm{H}$ NMR of $\mathbf{1}$ and 2 and barriers to rotation.

In addition, $\mathbf{2}$ is a solid and its X-Ray crystallographic analysis shows that the perfluorobenzyl and naphthalene rings are parallel. The $\mathrm{A}$ - and $\mathrm{B}$-rings are perpendicular with a dihedral angle at $88^{\circ}$ in the solid state. Also, the A- and Crings are $\pi$-stacked with a distance of $3.26 \AA$. Interestingly, this is closer than the interplane distance of $3.4 \AA$ between $\mathrm{C}_{6} \mathrm{H}_{6}$ and $\mathrm{C}_{6} \mathrm{~F}_{6}$ in the wellknown co-crystal. ${ }^{2}$ Our work in this area will be presented.

\section{CONCLUSION}

An effective system was designed to study intramolecular $\pi-\pi$ stacking interactions. New derivatives are currently prepared in order to increase the $\pi$ - $\pi$ stacking energy and understand the factors that control this system.

\section{ACKNOWLEDGEMENTS}

We gratefully acknowledge the Department of Chemistry of the University of Florida.

\section{REFERENCES}

${ }^{1}$ Knowles, R. R.; Jacobsen, E. N. Proc. Natl. Acad. Sci. 2010, 107, 20678.

${ }^{2}$ Meyer, E. A.; Castellano, R. K.; Diederich, F. Angew. Chem., Int. Ed. 2003, 42, 1210-1250.

${ }^{3}$ I. O. Sutherland, Annu. Rep. NMR Spectrosc., 1971, 4, 71-235. 